\title{
Article \\ Seismic Vulnerability Assessment of Historic Constructions in the Downtown of Mexico City
}

\author{
L. Gerardo F. Salazar ${ }^{1}\left(\mathbb{D}\right.$ and Tiago Miguel Ferreira ${ }^{2, *}$ (I)
}

1 Department of Civil Engineering, Faculty of Engineering, University of Porto, 4200-465 Porto, Portugal; gsalazar@fe.up.pt

2 Institute for Science and Innovation for Bio-Sustainability (IB-S), Department of Civil Engineering, University of Minho, 4800-058 Guimarães, Portugal

* Correspondence: tmferreira@civil.uminho.pt

Received: 15 December 2019; Accepted: 7 February 2020; Published: 10 February 2020

\begin{abstract}
Seismic risk is determined by the sum of multiple components produced by a certain seismic intensity, being represented by the seismic hazard, the structural vulnerability and the exposure of assets at a specified zone. Most of the methods and strategies applied to evaluate the vulnerability of historic constructions are specialized in buildings with higher importance, either public or private, by relegating ordinary dwellings to a second plane. On account of this, this paper aims to present a seismic vulnerability assessment, considering a limited urban area of the Historic Downtown of Mexico City (La Merced Neighborhood), thus showing the analysis of 166 historic buildings. The seismic vulnerability assessment of the area was performed resorting to a simplified seismic vulnerability assessment method, composed of both qualitative and quantitative parameters. To better manage and analyze the human and economic exposure, the results were integrated into a Geographic Information System (GIS) tool, which allowed to map vulnerability and damage scenarios for different earthquake intensities.
\end{abstract}

Keywords: seismic risk; vulnerability; cultural heritage; Mexico City; historic center

\section{Introduction}

As is widely known, while seismic hazard involves the probability of occurrence of a seismic event [1], which can be represented by an exposure model [2], seismic vulnerability can be defined as the intrinsic predisposition of an element to suffer damage from a seismic event of a given intensity. Specifically concerning Heritage Sites, the elements considered are the inherent features of a cultural heritage site, a group of buildings, monuments or objects, as well as their institutional and/or socio-economic context [3]. In terms of the vulnerability of historic buildings, it is fundamental that vulnerability studies address the assessment of potential damages and, based on those, discuss possible rehabilitation and/or retrofit interventions and supported pre- and post-disaster decisions [4-6].

Aimed at contributing to this discussion, a pilot area of the Mexico City Downtown is comprehensively investigated herein by analyzing and intercrossing its historical seismicity with the most relevant architectural, construction and structural features of the buildings. For this purpose, a matrix of thirty-six typologies of residential and historical buildings was assessed, resorting to a simplified seismic vulnerability assessment. Over this assessment, the identification of the most vulnerable aspects of the building stock allowed the presentation of damage scenarios, generated by different macroseismic intensities. Geographical Information Systems (GIS) tools play an essential role in the establishment of urban management, civil protection, and risk disaster strategies. For that reason, this analysis was established by mapping and discussing all outputs through the free and open-source software QGIS ver. 3.8.1 (QGIS Development Team: Zanzibar) [7]. 
The primary motivation of this work lies in the fact that, although Mexico City has been affected by multiple disastrous earthquakes over the last decades, no seismic vulnerability assessment tools or methods have been proposed to evaluate the vulnerability of its historical constructions. As discussed in this paper, among many other relevant outputs, such a tool would allow for the definition of specific targets aimed at supporting the preservation of the cultural value of this heritage and to prevent (or at least to mitigate) economic or human losses in the case of a future earthquake event.

\section{A Brief History of Seismicity in Mexico City}

The Mexican territory is characterized by high seismic activity. Located next to the Circum-Pacific Belt and the Cocos, Ribera, North American and Pacific tectonic plates, the site is rich in geologic effects, particularly subduction (North American and Cocos Plates) and sliding (North American and Pacific Plates). Furthermore, the high volcanic activity recorded in the last years is also an important source of seismic activity (e.g., the Popocatepetl or Colima volcanoes). The selected study area is located in Mexico City within the limits of the borough of Cuauhtémoc, well-known as the La Merced neighborhood. This area comprises around three hundred buildings, both modern and historic.

The soil properties of Mexico City are classified into three zones, illustrated in the seismic micro-zoning map (Figure 1a), highlighting that the increase of wave vibrations depends on location. In Zone I (grey), the soil presents high resistance and less compressibility, with interlayers of sand in a cohesive condition; thus, the amplification of the seismic waves is reduced (hard rock). In Zone II (yellow), the characterization of the soil is sandy and silty with interlayers of clay; it is called the transition zone, with higher amplification waves effects than in Zone I. Finally, Zone III (green, dark green, orange, red), which comprises the former Texcoco lake [8], is linked to soft highly compressive soils (clays). For this assessment, the location of the building stock in La Merced is defined within the limits of Zone III indicated in Figure 1a, which is known as a zone with high seismic waves. Therefore, the interest and some antecedents of this study are described, considering that the study area is not only settled over lacustrine soil but also founded on a high seismicity area.

According to the literature [9-13], in 1845, a seism occurred with an epicenter along the coast of Guerrero. The reason for the earthquake was most likely a subduction effect that struck Mexico City and its surroundings, causing extensive damages to St. Teresa's Temple, thus causing the collapse of its cupola. Some authors and seismologists specialized in the history of seismicity in Mexico indicate that this event could have had a direct precedent linked to the earthquakes that occurred in 1957, 1985 [11] and 2017. Some other high seismic events were recorded during the 19th century and published by [10,12]; one occurred over Oaxaca in 1800, and another occurred along the north part of Michoacán in 1858. Throughout the 20th century, upon the evolution of the seismic instrumentation, more than 40 seismic events ranging between 7.0 and 7.9 on the Richter scale were recorded in Mexico City, in addition to six seismic events higher than 8.0 [12].

At the beginning of the 20th century, Mexico City was affected by various subduction events, thus producing a significant amount of losses, such as those that occurred in 1907 and 1909 with magnitudes of 7.9 and 7.5, respectively [12]. In 1957, there was an earthquake with an epicenter over the coast of Acapulco, Guerrero, with a magnitude of 7.8 on the Richter scale, thus causing several damages in the central zone of the country, especially in Mexico City, reporting 700 deaths and over 2500 injuries [9].

Some years later, in 1979, the city was shaken by an earthquake with an epicentre in Petatlán (Guerrero), which reached a magnitude of 7.6 on the Richter scale [12]. However, in 1985, an 8.1 magnitude earthquake with epicenter along the Coast of Michoacán devastated Mexico City, causing more than 6500 deaths, 50,000 injuries and 770 collapsed buildings [9,14]. Two earthquakes occurred in 1999, affecting the states of Puebla and Oaxaca, with a magnitude of 7 and 7.5 on the Richter scale, respectively. The latter produced damages in public buildings (i.e., schools or temples considered historical constructions), reporting 52 fatalities and inducing the collapse not only of monumental buildings but also of dwellings made of adobe. 
Recently, in 2017, two intense earthquakes occurred on 7th of September and 19th of September. The first (7th September) occurred near the coast of Oaxaca with a subduction event of $\mathrm{M}_{\mathrm{s}}=8.2$, while the second was a local event with an epicenter located in Axochiapan, Morelos with $M_{s}=7.1$ (19th September). Due to these seismic events, a large number of losses affecting immovable cultural heritage were reported in different zones of the Central and Southwest part of the country. The earthquake of the 7th of September 2017 could correspond to the absence of seismic activity located at the Tehuantepec Gap, in the State of Oaxaca, as seen in Figure 1b.

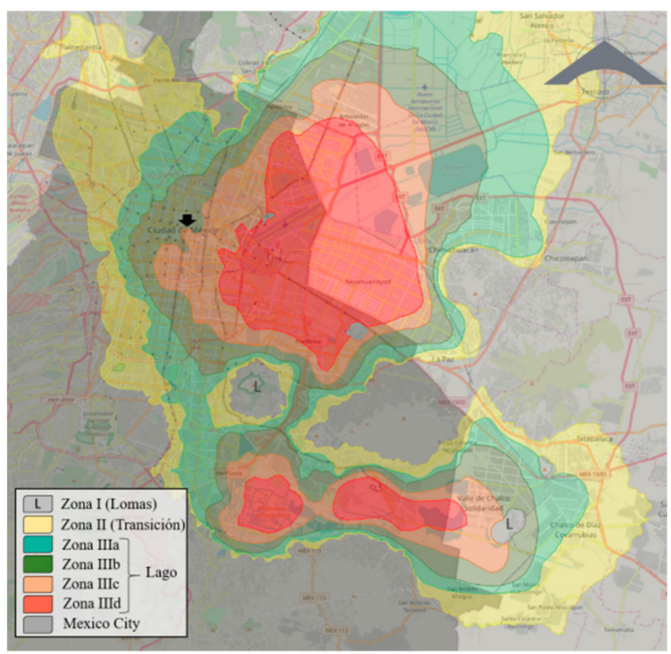

(a)

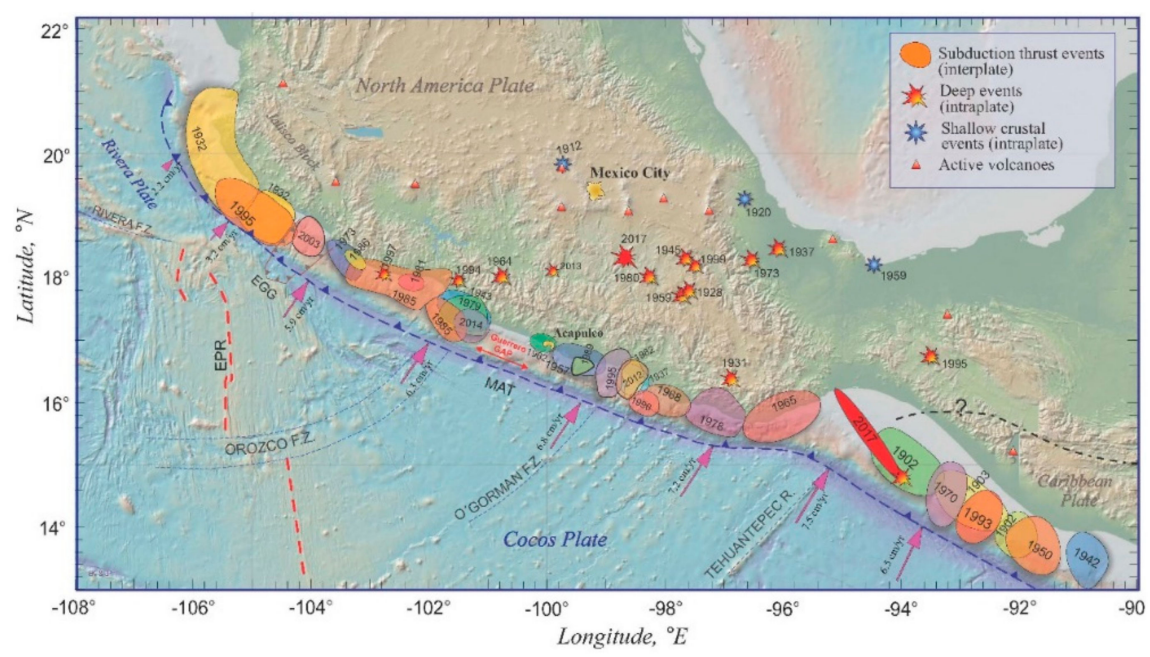

(b)

Figure 1. (a) Seismic zonation of Mexico City with the location of the study area. Source: SPC/UNAM/SEDUVI; (b) Most significant seismic events that occurred in the region over the last century. Source: Geophysics Institute UNAM [15].

Figure $1 \mathrm{~b}$ shows not only the earthquake near the Tehuantepec Gap but also the seismic activity that occurred during the 20th century and was recorded by the National Seismologic Service of Mexico (SSN). The map (Figure 1b) depicts, along the coast of Guerrero, the absence of seismic activity, which is well-known as the Guerrero Gap. This Gap, located about $300 \mathrm{~km}$ from Mexico City, can signify possible future seismic events produced by interplate movements (i.e., subduction trust events), with similar or higher magnitudes than those that occurred in 1985 and 2017 with significant impact on Mexico City. However, the consequences of these seismic events in the city do not depend only on 
interplate movements, but also on volcanic activity (i.e., the Popocatepetl volcano) [13], denoting a seismic risk between two possible geologic phenomena.

\section{Buildings Exposure Model}

Numerous researches have proposed different methodologies to achieve closer approaches to the history of construction and architecture related to buildings from the 16th century to the beginning of the 20th century. Most of the buildings in the historic center are considered of cultural heritage, catalogued by the National Institution of Anthropology and History (INAH) or by the National Institute of the Fine Arts (Instituto Nacional de Bellas Artes-INBA). Nonetheless, over their lifespan, some of the buildings have been refurbished or retrofitted, resorting to different construction technologies and materials, some of them poorly compatible with the original characteristics of these buildings. A categorical example of such inadequate intervention is the use of concrete or cement-based materials, which are chemically, physically and mechanically incompatible with traditional construction technologies. A comprehensive discussion on this aspect was recently given by Correia Lopes et al. [16]. To determine the characterization of the buildings, highlighting the wide ranges and complex task of collecting the data, the typology matrix presented in Tables 1-3 was established based on: (1) post-seismic damage data collected and recorded by the Ministry of Housing and Urban Development (SEDUVI), the Ministry of Construction (SOBSE) and the Civil Protection bodies (SPC) after the 19th of September 2017 earthquake; (2) digital visual inspection using Google Earth ver. 7.3.2 (Google: Mountain View, CA, USA) aerial and Street View; (3) a database provided by the Authority of the Historic Center (ACH) with general data from a few buildings (conservation state, age, characteristics of the walls, floors and roofs, interventions history); (4) literature published by various authors, namely research articles from the Historical Monuments National Coordination (CNMH); (5) on-site reports for 125 residential buildings; and (6) analysis of historical photos gathered in the scope of the project 'Memory of the City' of the Central Zone of Mexico City (coordinated by INAH and CNMH).

Table 1. Final matrix typology. Source: created by the authors.

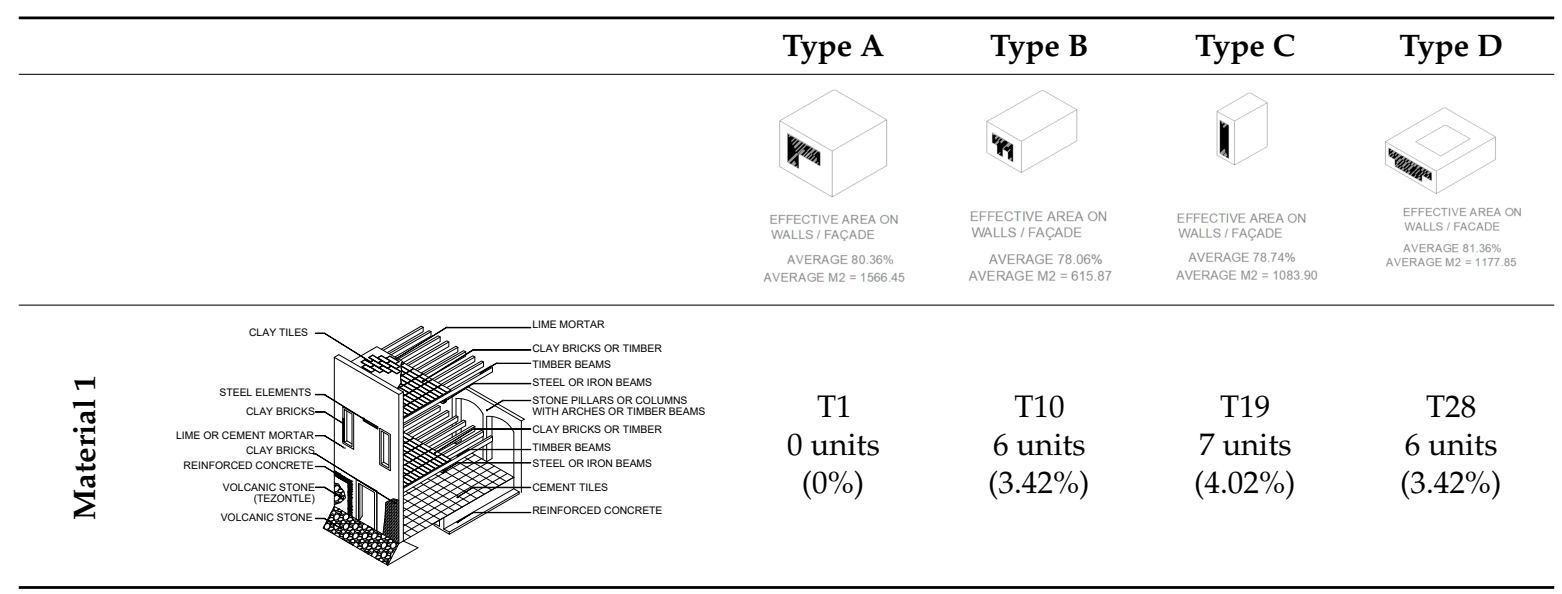

Regarding material typology, M3 and M2 cover the largest quantity of buildings with 30 and 28, respectively, after which M5, M4, M1 and M7 have 26, 23, 19 and 15 buildings, respectively, whereas the types with the smallest number of buildings are the M9, M8 and M6 with 9, 8 and 8, respectively. With no cases identified, building typologies T1, T4, T6, T7 and T36 are not considered for the study area. However, they can be extrapolated to the city center locating similar constructions. The major represented building typologies, with 14 buildings for each (around 8\% of the building stock) are typologies T11 (geometry type B and material M2) and T12 (geometry type B and material M3). 
Table 2. Final matrix typology. Source: created by the authors.

\begin{tabular}{|c|c|c|c|c|c|}
\hline & & Type A & Type B & Type C & Type D \\
\hline & & $\begin{array}{l}\text { EFFECTIVEAREA ON } \\
\text { WALLIIIFCADE } \\
\text { AVERAGE } 80.36 \% \\
\text { AVERAGE M2 }=1566.45\end{array}$ & $\begin{array}{l}\text { EEFECTVE AREA ON } \\
\text { WALLSIIFACADE } \\
\text { AVERAGE } 78.06 \% \\
\text { AVERAGE M2 }=615.87\end{array}$ & 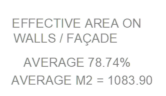 & 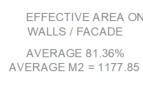 \\
\hline 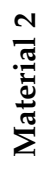 & 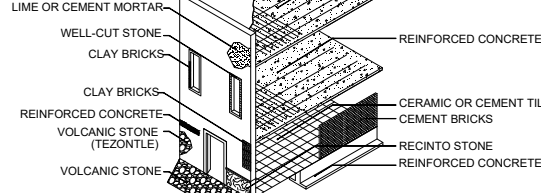 & $\begin{array}{c}\mathrm{T} 2 \\
3 \text { units } \\
(1.61 \%)\end{array}$ & $\begin{array}{c}\mathrm{T} 11 \\
14 \text { units } \\
(8.24 \%)\end{array}$ & $\begin{array}{c}\text { T20 } \\
5 \text { units } \\
(2.82 \%)\end{array}$ & $\begin{array}{c}\text { T29 } \\
6 \text { units } \\
(3.42 \%)\end{array}$ \\
\hline 党 & 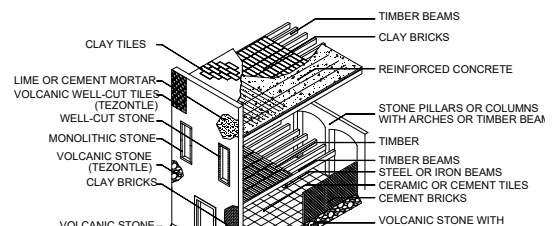 & $\begin{array}{c}\text { T3 } \\
3 \text { units } \\
(1.61 \%)\end{array}$ & $\begin{array}{c}\mathrm{T} 12 \\
14 \text { units } \\
(8.24 \%)\end{array}$ & $\begin{array}{c}\text { T21 } \\
5 \text { units } \\
(2.82 \%)\end{array}$ & $\begin{array}{c}\text { T30 } \\
8 \text { units } \\
(4.63 \%)\end{array}$ \\
\hline 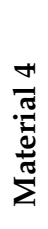 & 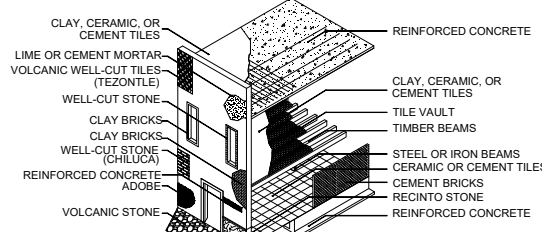 & $\begin{array}{c}\mathrm{T} 4 \\
0 \text { units } \\
(0 \%)\end{array}$ & $\begin{array}{c}\text { T13 } \\
10 \text { units } \\
(5.83 \%)\end{array}$ & $\begin{array}{c}\text { T22 } \\
9 \text { units } \\
(5.23 \%)\end{array}$ & $\begin{array}{c}\text { T31 } \\
14 \text { units } \\
(8.24 \%)\end{array}$ \\
\hline 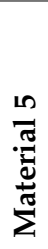 & LIME-SAND.SOLL MORTAR & $\begin{array}{c}\mathrm{T} 5 \\
4 \text { units } \\
(2.21 \%)\end{array}$ & $\begin{array}{c}\mathrm{T} 14 \\
12 \text { units } \\
(7.04 \%)\end{array}$ & $\begin{array}{c}\text { T23 } \\
4 \text { units } \\
(2.21 \%)\end{array}$ & $\begin{array}{c}\text { T32 } \\
6 \text { units } \\
(3.42 \%)\end{array}$ \\
\hline
\end{tabular}

The next on the list is typology T14 with 7\% and 12 buildings, which results from the consideration of geometry B and material M5; and T13 with approximately $5.8 \%$ corresponding to 10 buildings (B and M4). These are followed by T34 (D and M7) and T22 (C and M4), which have a percentage of almost $5.2 \%$ each (nine buildings respectively). T30 (correlation between D and M3) has $4.6 \%$ that is equivalent to eight buildings. The ratio of T10 (B and M1), T28 (D and M1), T29 (D and M2) and T32 (D and M5) is almost 3.4\% each (six buildings each). Typologies T2, T3, T5, T8, T9, T15, T16, T17, T18, T19, T20, T21, T23, T24, T25, T26, T27, T31, T33 and T35 have between $0.4 \%$ (one building) and $2.9 \%$ (five buildings) on the analyzed site. 
Table 3. Final matrix typology. Source: created by the authors.

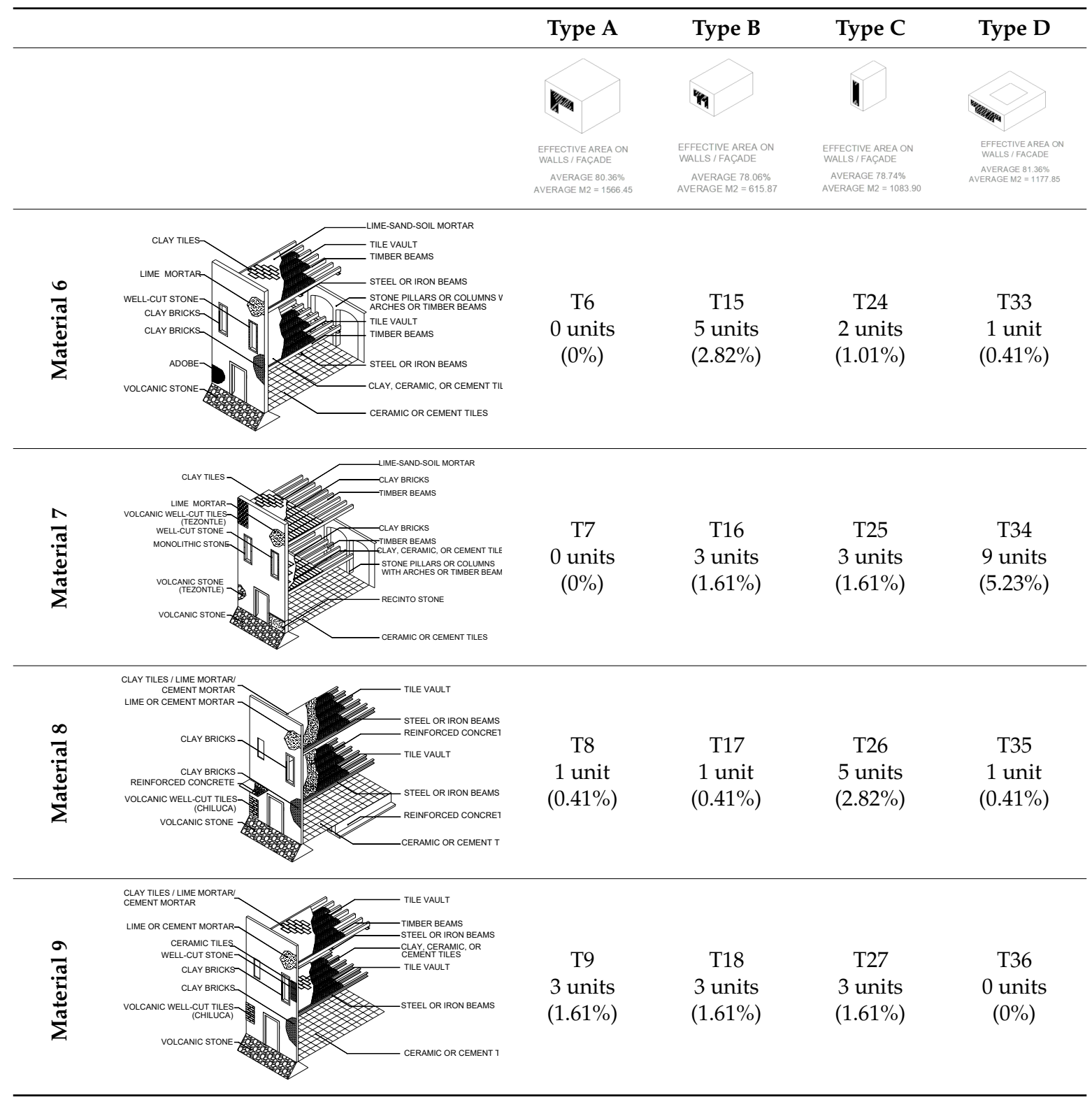

\section{Seismic Vulnerability Assessment}

Following the proposal of Gruppo Nazionale per la Difesa dai Terremoti (GNDT) [17], a simplified seismic vulnerability assessment approach is used in this work. The method was proposed by Ferreira et al. [18] to assess the seismic vulnerability of traditional masonry buildings and to estimate damages and post-seismic losses for different macroseismic scenarios [19]. The method is based on the assessment of 14 parameters within the vulnerability index, organized in four groups: (1) structural building system; (2) irregularities and interaction; (3) floor slabs and roofs; and (4) conservation status and other elements. The first group (Group 1) involves the building resisting system, namely type P1, the quality of the resisting system (P2), the shear strength capacity of the building (P3), the maximum distance between walls whose indicator constitutes a potential out-of-plane failure mechanism (P4), the number of floors (P5) and the geotechnical conditions of the foundations (P6). The second group (Group 2) considers the irregularities and interaction between adjacent buildings (P7), the regularities in plan (P8) and height (P9) and the alignment of the openings (P10). The parameters integrated into the third group (Group 3) are the quality of the horizontal supporting structures, namely of the 
horizontal diaphragms (P11), and the roofing system (P12). Finally, the fourth group (Group 4) is linked to the conservation status, considering the fragilities of the building (P13) and the characteristics of non-structural elements (P14).

The vulnerability parameters are influenced by a vulnerability class (A, B, C and D), by choosing the best-described vulnerability option for each parameter, between the values 0 to 50 multiplied by a weight $\left(P_{i}\right)$, which ranges from 0.5 (lower-ranking) to 1.5 (higher-ranking). A vulnerability index $\left(I_{v}^{*}\right)$ value ranging from 0 to 650 can then be obtained. Furthermore, for ease of use, this value is usually normalized $\left(I_{V}\right)$ between 0 and 100. On account of this, the simplified vulnerability assessment method was applied to the study area in Mexico City through a typological-based approach by establishing some empirical facts. As will be discussed further on, this vulnerability indicator can be used as an early step for estimating damages and losses [20].

\subsection{Seismic Vulnerability Assessment and Damage Scenarios}

Once data is collected, the vulnerability assessment was performed for a historic area of Mexico City. The vulnerability assessment is performed herein adopting a typological-based procedure which consists of a pre-assessment of the seismic vulnerability of each one of the typologies identified in Section 3, through the assessment of eight specific vulnerability assessment parameters (P1, P2, P4, P5, P8, P9, P11 and P12), which, as can be seen in Table 2, focus on the structural characteristics of the buildings (Group 1), on their irregularities and the interaction between adjacent buildings (Group 2) and the characteristics of their floor slabs and roof (Group 3), see Table 4.

Table 4. Vulnerability index, according to [18], modified for the study area.

\begin{tabular}{|c|c|c|c|c|c|c|c|}
\hline & \multirow{2}{*}{$\begin{array}{c}\text { Vulnerability Index }\left(I_{v}\right) \\
\text { Parameters }\end{array}$} & \multicolumn{4}{|c|}{ Class } & \multirow{2}{*}{$\frac{\text { Weight }}{\left(\boldsymbol{P}_{\boldsymbol{i}}\right)}$} & \multirow[t]{2}{*}{ Vulnerability Index } \\
\hline & & $\mathbf{A}$ & B & $\mathrm{C}$ & $\mathbf{D}$ & & \\
\hline 1. & Structural building system & & & & & & \multirow{6}{*}{$I_{V}^{c c}=\sum_{i=1}^{13} C_{V I} \times P_{i}$} \\
\hline P1 & Type of resisting system & 0 & 5 & 20 & 50 & 0.75 & \\
\hline $\mathrm{P} 2$ & Quality of the resisting system & 0 & 5 & 20 & 50 & 1.00 & \\
\hline $\mathrm{P} 4$ & Maximum distance between walls & 0 & 5 & 20 & 50 & 0.50 & \\
\hline P5 & Number of floors & 0 & 5 & 20 & 50 & 1.50 & \\
\hline P6 & Location and soil conditions & 0 & 5 & 20 & 50 & 0.75 & \\
\hline 2. & Irregularities and interaction & & & & & & \multirow{5}{*}{$0 \leq I_{\mathcal{v}}^{c c} \leq 575$} \\
\hline P7 & Aggregate position and interaction & 0 & 5 & 20 & 50 & 1.50 & \\
\hline P8 & Plan configuration & 0 & 5 & 20 & 50 & 0.75 & \\
\hline P9 & Regularity in height & 0 & 5 & 20 & 50 & 0.75 & \\
\hline P10 & Wall façade openings and alignments & 0 & 5 & 20 & 50 & 0.50 & \\
\hline 3. & Floor slabs and roofs & & & & & & \multirow{6}{*}{$\begin{array}{l}\text { Normalized index } \\
0 \leq I_{v} \leq 100\end{array}$} \\
\hline P11 & Horizontal diaphragms & 0 & 5 & 20 & 50 & 1.00 & \\
\hline P12 & Roofing system & 0 & 5 & 20 & 50 & 1.00 & \\
\hline 4. & \multicolumn{6}{|c|}{ Conservation status and other elements } & \\
\hline P13 & Fragilities and conservation state & 0 & 5 & 20 & 50 & 1.00 & \\
\hline P14 & Non-structural elements & 0 & 5 & 20 & 50 & 0.50 & \\
\hline
\end{tabular}

After the eight refereed parameters have been evaluated (according to the aforementioned typological-based approach), the vulnerability analysis is accomplished by evaluating the remaining parameters of the vulnerability assessment methodology, namely parameters P6, P7, P10, P13 and P14. Following this strategy, it was thus possible to perform a complete vulnerability assessment of the whole study area. It is worth noting, that because of the nature of the data required to evaluate Parameter 3, this parameter was neglected in the present study. For this reason, instead of having 650 as a maximum vulnerability index value, the vulnerability index value is limited in this analysis to $575\left(I_{v}^{c c}\right)$. 


\subsection{Analysis and Discussion of the Results}

The vulnerability assessment method was applied to 166 historical buildings, resulting in a mean value of the seismic vulnerability index $\left(I_{v}^{c c}\right)$ of 45.91 . Non-historic buildings, which include reinforced concrete (RC) and rehabilitated ones, fall outside the scope of the study and are omitted from the data. Figure 2 presents the results of $I_{v}^{c c}$ for the study area, whereas Figure 3a depicts the distribution of the vulnerability index $\left(I_{v}^{c c}\right)$ for the 166 buildings. Almost $75 \%$ of the assessed buildings had a vulnerability index value $\left(I_{v}\right)$ greater than 40 (i.e., equivalent to vulnerability class $\mathrm{A}$ in the European Macroseismic Scale (EMS-98) [18]). While the maximum and minimum values obtained from the assessment were 75 and 27, respectively, the standard deviation value obtained $\left(\sigma I_{v}^{c c}\right)$ was 8.34 . The lower and the upper bond values of the vulnerability distribution are also used in the analyses presented in the following.

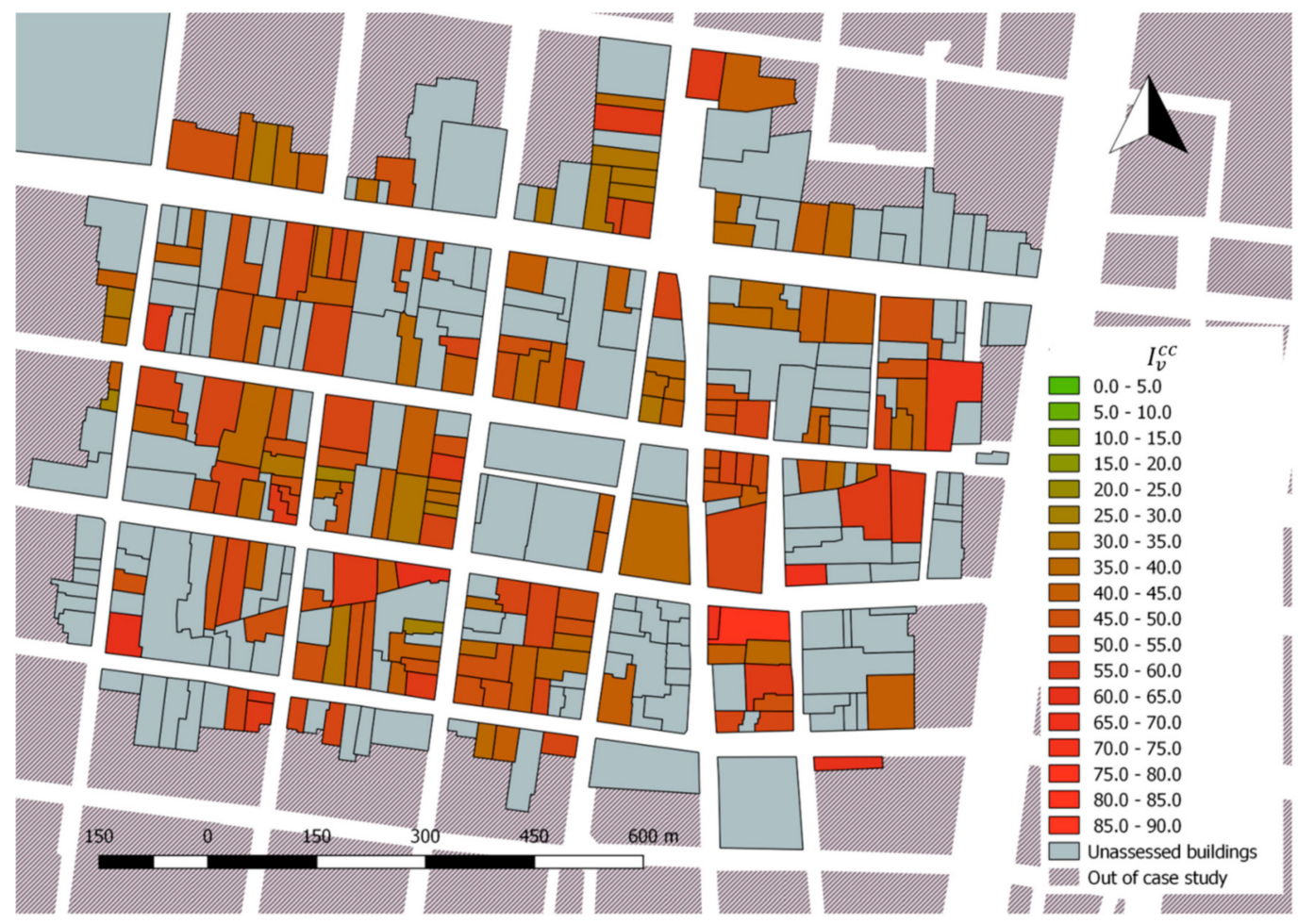

Figure 2. Mapping of the vulnerability index $I_{v}^{c c}$ in Mexico City (La Merced).

Figure $3 \mathrm{~b}$ presents the frequency distributions of the most important parameters in terms of their influence on the vulnerability index definition. As observed, class D overcomes 50\% for parameters $\mathrm{P} 4$, P9, P10, P12 and 14 (i.e., the distance between walls, regularity in height, openings and alignments, roofing system and non-structural elements) evidencing a significant number of parameters related to the irregularity and interaction of the buildings. The combination of class $\mathrm{D}$ and class $\mathrm{C}$ covers more than 50\% for parameters P1, P6, P8, P11 and P13 (i.e., type of resisting system, location and soil conditions, plan configuration, horizontal diaphragms, and fragilities and conservation state); at this point, the class D for P1, P6, P8, P11 and P13 is lower than parameters P4, P9, P10, P12 and 14; however, it is still significant with excessive deficiency in the structural building system (Group 1), and the irregularities and interaction (Group 2). The presence of parameters A and B (i.e., the classes corresponding to lower vulnerability) is dominant in the parameters P2, P5 and P7 (quality of the resisting system, number of floors and aggregate position and interaction). 


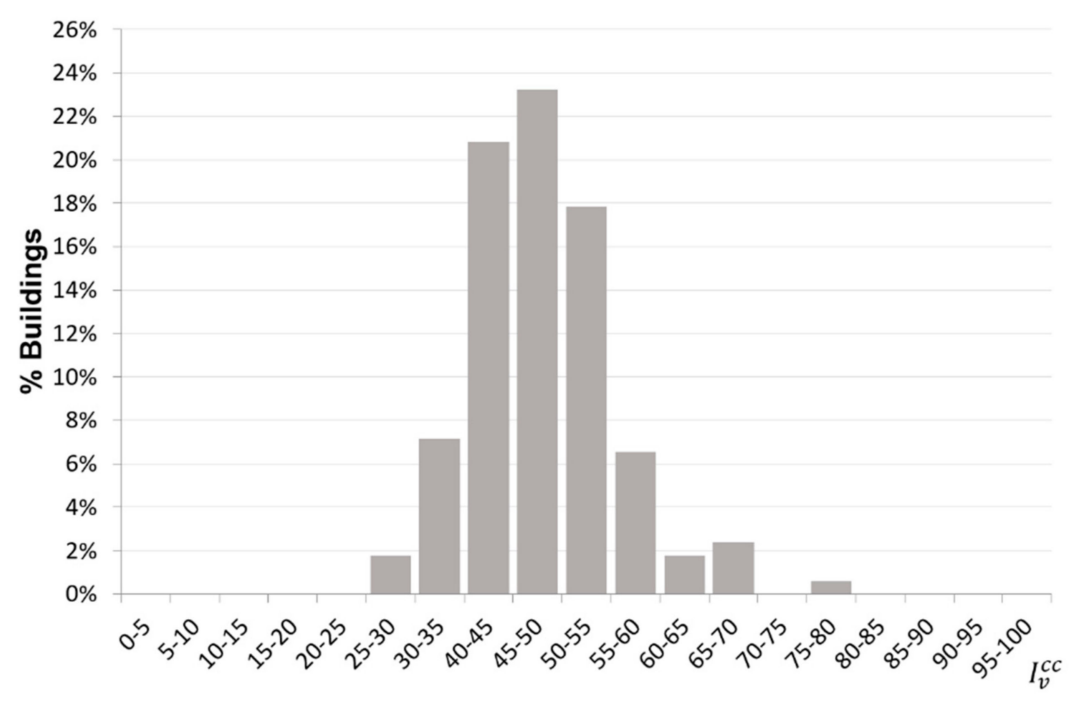

(a)

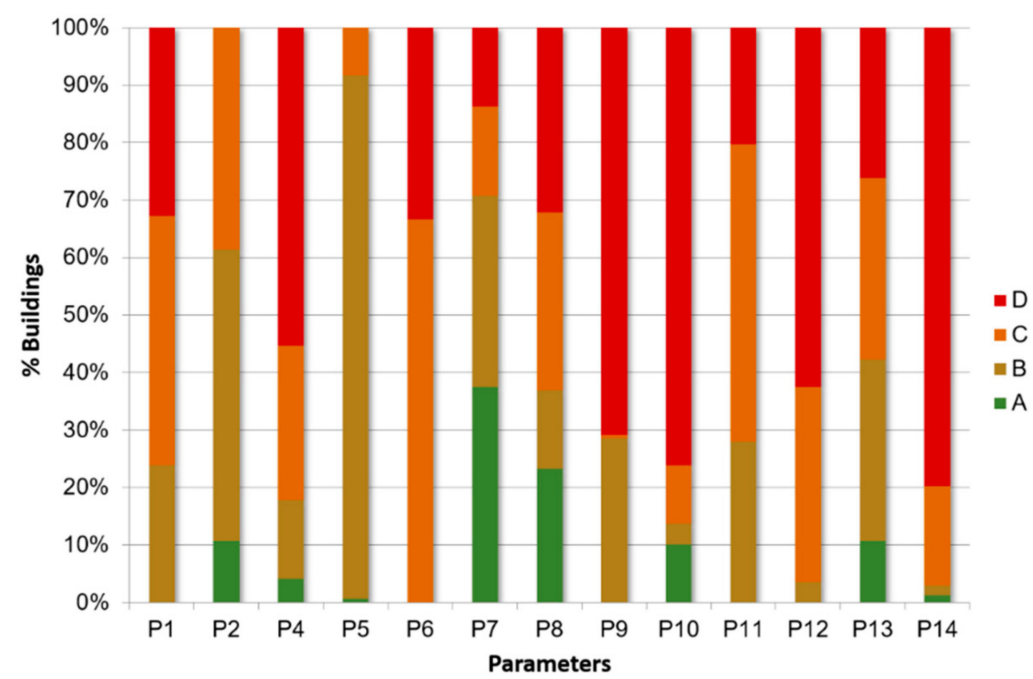

(b)

Figure 3. (a) Histogram representing the vulnerability index; (b) Frequency distributions for parameters $I_{v}^{c c}$.

Some of the highly vulnerable parameters are related to geometry, such as the alignment of the openings (P10), the height (P9), the characteristics of the foundations when interacting with the soil conditions (P6), the connections between vertical and horizontal systems and the increase of the stiffness on the horizontal diaphragm systems. The latter (i.e., increase of stiffness) is conceivably linked to the incompatibility of the systems (P1, P12), the physical or mechanical properties of the wall itself (P2), and the non-structural elements (P14). Even though the weight $\left(P_{i}\right)$ of parameters P1, P2, P11, P12 and P13 is 1.0 or lower (see Table 4), their individual analysis (i.e., non-typological-based method selection) is essential because the set of these parameters reflects higher levels of individual vulnerability. The following figures illustrate some parameters with major class D such as P4 (Figure 4a), P9 (Figure 4b), P10 (Figure 4c), P12 (Figure 4d) and 14 (Figure 4f). The importance of the visual inspection considering the maintenance and current condition is relevant for the seismic vulnerability assessment; for that reason, P13 (Figure 4e) is depicted, thus illustrating the conservation level for each building. 


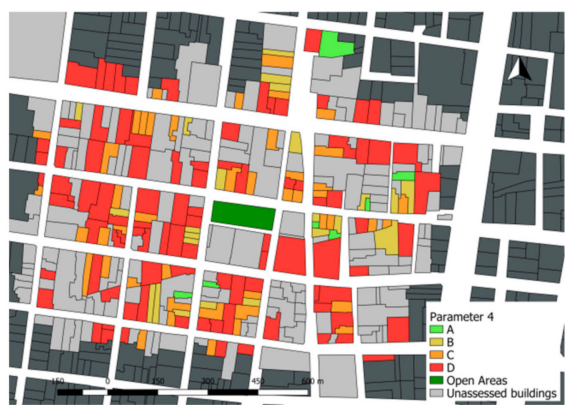

(a)

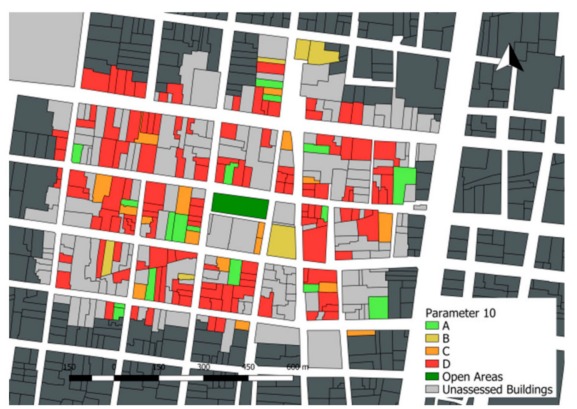

(c)

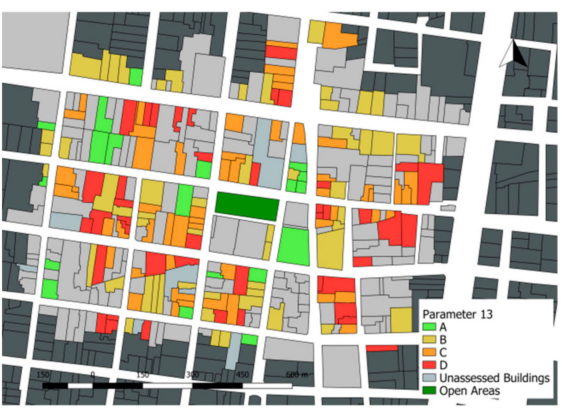

(e)

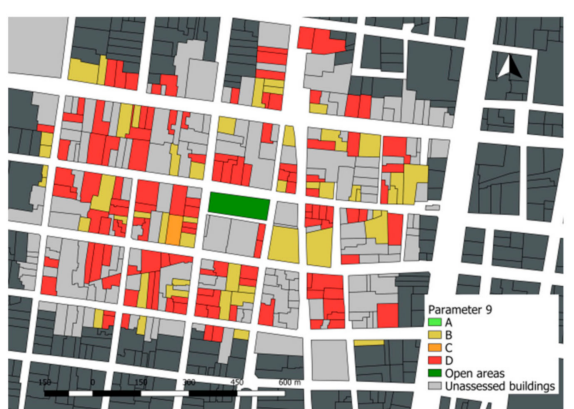

(b)

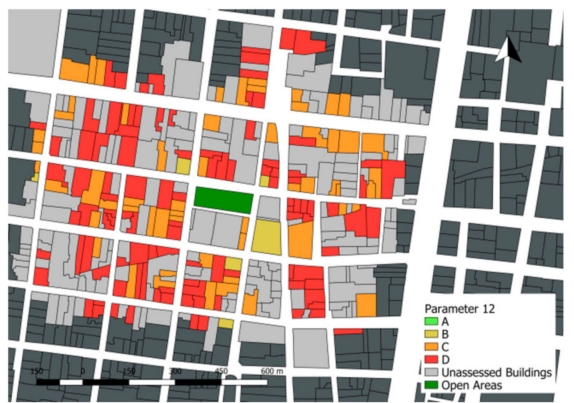

(d)

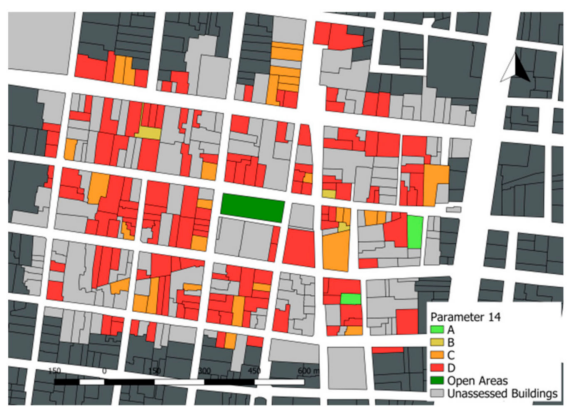

(f)

Figure 4. Mapping of (a) parameter P4, (b) parameter P9, (c) parameter P10, (d) parameter P12, (e) parameter P13 and(f) parameter P14. See Table 1 for a description of the parameters.

\subsection{Damage Distribution and Loss Scenario}

To obtain the damage distribution and loss scenario, the computation of mean damage grade must be considered, through either absolute or relative vulnerability results, depending on the selected methodology [21]. The absolute vulnerability represents the damage as a function of the seismic intensity, or it can be considered as the damage condition attributed to a given seismic intensity. On the contrary, the relative vulnerability is determined by empirical or experimental data, without correlating the damage and the seismic intensity. For this paper, the analysis will be considered absolute. Accordingly, to represent the grade of damage linked to a seismic event, EMS-98 can be used [22]. Nevertheless, the damage grade can be associated, employing phenomena that occurred in a particular location, whose aims entail the assessment of cultural heritage. Thereby, the mean damage grades $\left(\mu_{D}\right)$ are estimated for different macro-seismic intensities based on the previous results of the vulnerability index. Under the analytical expression that correlates hazard and a mean damage grade $\left(0 \leq \mu_{D} \leq 5\right)$ of the damage distribution, the vulnerability value $(V)$ is obtained through the Equations (1) and (2) [23]: 


$$
\begin{gathered}
\mu_{D}=2.5\left[I+\tanh \left(\frac{6.25 \times V-13.1}{Q}\right)\right] ; 0 \leq \mu_{D} \leq 5 \\
V=0.592+0.0057 \times I_{v}^{c c}
\end{gathered}
$$

According to equations above, the vulnerability index value $(V)$ determines the position of the curve, whereas the ductility factor $(Q)$ limits the slope of the vulnerability function (e.g., the rate of damage increases with rising intensity). For the computation of the mean damage grades $\left(\mu_{D}\right)$, the input values were the proposed seismic intensities (I) between the range of $\mathrm{V}$ and XII, the vulnerability index $\left(I_{v}^{c c}\right)$ calculated previously with a mean value of 45.91 and the proposed ductility factor $(Q)$ of 2.0. The $Q$ factor is based on similar values recommended by the local code (RCDF-NTC) [24] for equivalent buildings. In summary, the vulnerability index value, obtained in the prior assessment $\left(I_{v}^{c c}\right)$, is associated with the vulnerability index $(V)$ through the macroseismic approach seen in Equations (1) and (2). Therefore, the calculation of the mean damage grades $\left(\mu_{D}\right)$, and the subsequent estimations of physical, economic and human losses are calculated, by following the initial mean vulnerability index value $\left(I_{v}^{c c}\right)[18]$.

Figure 5a shows the vulnerability curves obtained for the mean value of the vulnerability index $\left(I_{v}^{c c}\right.$ mean) and the lower and upper bound ranges $\left(I_{v}^{c c}\right.$ mean $-2 \sigma I_{v}^{c c} ; I_{v}^{c c}$ mean $-1 \sigma I_{v}^{c c} ; I_{v}^{c c}$ mean + $1 \sigma I_{v}^{c c} ; I_{v}^{c c}$ mean $\left.+2 \sigma I_{v}^{c c}\right)$ for events with macroseismic intensities ranging from $V$ to XII. Thus, from an overall view, the estimated damages range from 1.02 to 2.29 corresponds to the earthquake scenario of $I_{E M S-98}=V I I$, the range from 2.06 to 3.48 corresponds to $I_{E M S-98}=V I I I$ and the range from 3.28 to 4.31 is linked to $I_{E M S-98}=I X$. The evaluation shows alarming results, due to the high estimation represented by moderate damages $\left(2 \leq \mu_{D}<3\right)$ at $I_{E M S-98}=V I I$, severe damages $\left(3 \leq \mu_{D}<4\right)$ at $I_{E M S-98}=$ VIII and possible collapses $\left(4 \leq \mu_{D}<5\right)$ at $I_{E M S-98}=I X$.

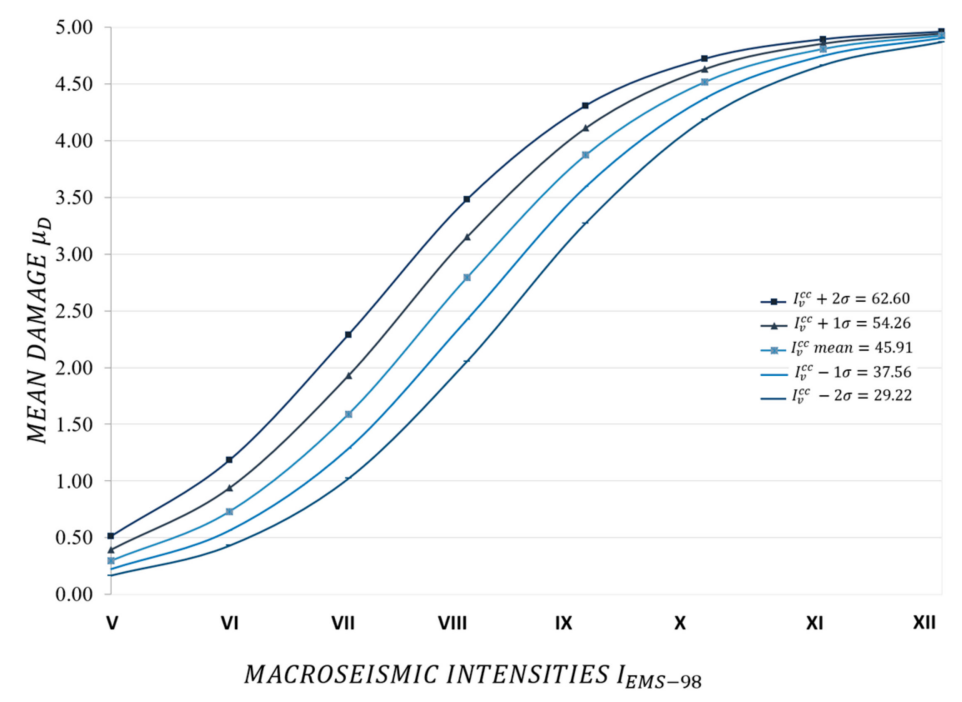

(a)

Figure 5. Cont. 


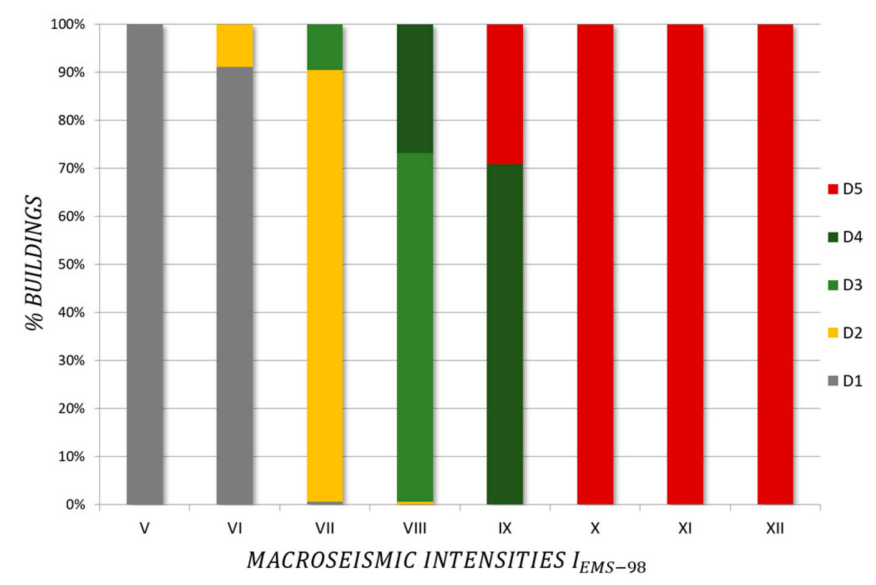

(b)

Figure 5. (a) Vulnerability curves and mean damage grade distribution for $I_{v}^{c c}$ mean $=45.91$ and intensities $I_{E M S-98}$ from V to XII; (b) Estimation percentage of buildings damaged by macroseismic intensity, $I_{v}^{c c}$ mean $=45.91$.

Figure $5 \mathrm{~b}$ depicts the distribution of buildings for each level of damage, associated with each level of macroseismic intensity from $I_{E M S-98}=V$ to $I_{E M S-98}=X I I$. For $I_{E M S-98}=V I$, the seismic scenario is characterised by moderate damages, thus evidencing the concentration of damage in grade D2, with a residual amount of D3 (i.e., about $10 \%$ ). For $I_{E M S-98}=V I I I$, approximately $72 \%$ of buildings denote a damage grade D3, and $28 \%$ a corresponding damage grade of D4. Considering a macroseismic intensity of $I_{E M S-98}=I X, 73 \%$ of the buildings would have a damage grade of D4, whereas the $26 \%$ would present a damage class of D5.

The damage assessment is an initial step to measure the risk linked to economic and human losses. These studies allow the spatial the global damage distribution, and the representation of the building stock analysis, by integrating GIS tools. The mapping damage distribution enables the practical identification of more vulnerable zones with its correspondent specific constructions, thus enhancing the decision-making for urban management and civil protection strategies [25]. The damage distribution scenarios are presented in Figure 6a (for $\left.I_{E M S-98}=V I I\right)$, Figure $6 \mathrm{~b}\left(I_{E M S-98}=V I I I\right)$ and Figure $6 c\left(I_{E M S-98}=I X\right)$ presenting the mean damage grade, the non-assessed buildings and the constructions out of the study area.

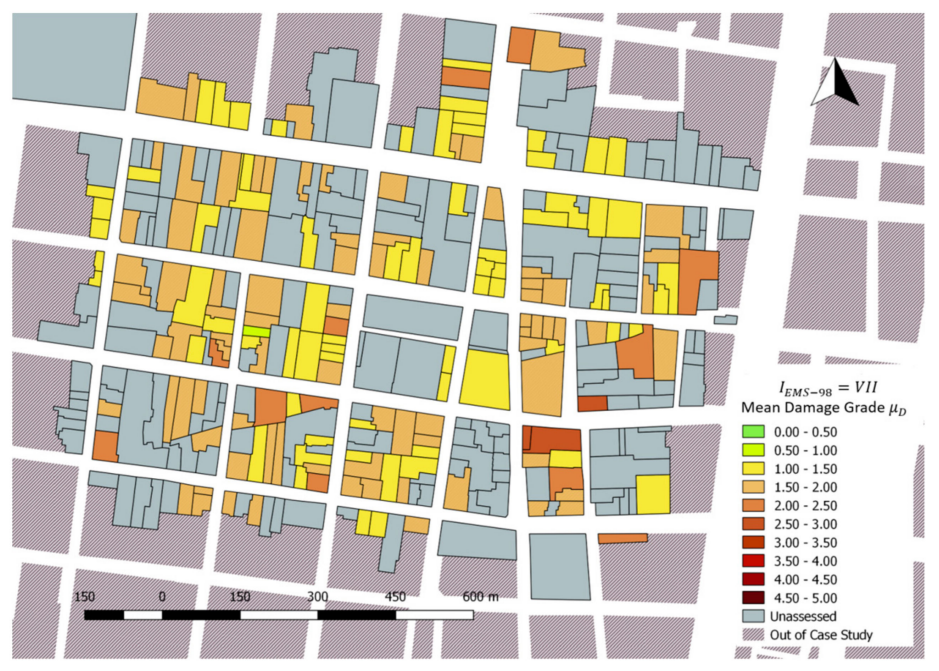

(a)

Figure 6. Cont. 


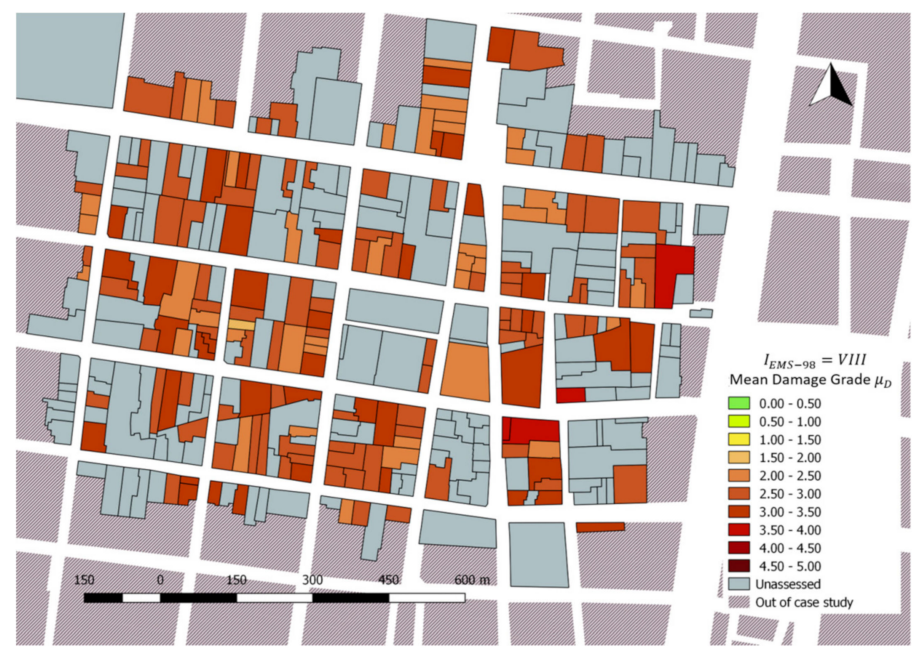

(b)

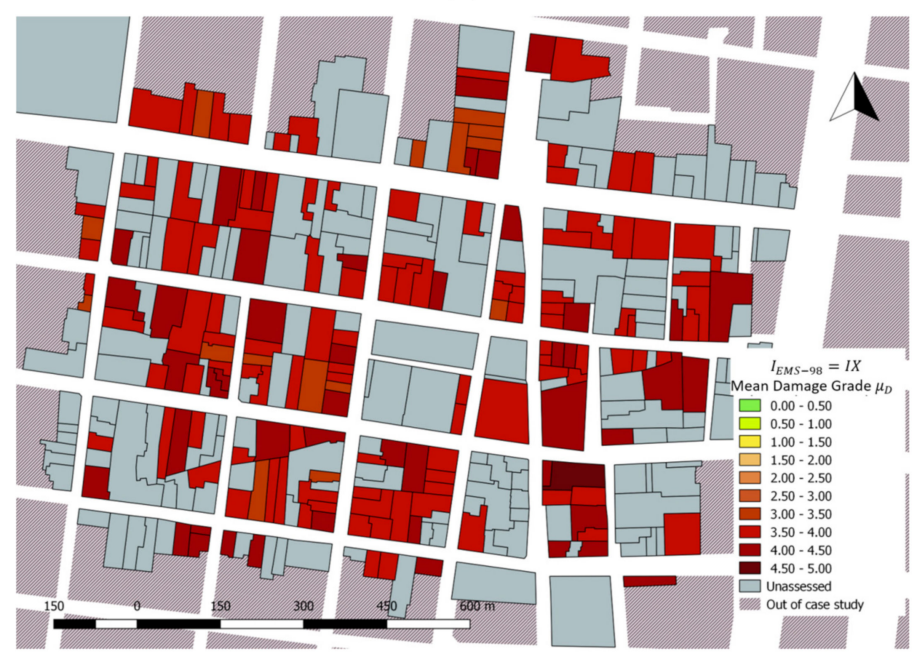

(c)

Figure 6. (a) Damage distribution for a macroseismic intensity of $I_{E M S-98}=V I I$; (b) Damage distribution for a macroseismic intensity of $I_{E M S-98}=V I I I$; (c) Damage distribution for a macroseismic intensity of $I_{E M S-98}=I X$.

\subsection{Fragility Curves}

Based on a probabilistic approach, the physical building damage distributions are possible to determine through the beta probability function for specific building typologies. Fragility curves are possibly some of the most accepted and used methods for representing estimations of damage, thus defining probabilities that can exceed a specific damage grade $D_{k}(\in[0 ; 5])$ [18]. Fragility curves establish a relationship between five damage states and earthquake intensity, entailed by continuous probability functions, which express the conditional cumulative probability when reaching or exceeding a certain degree of damage state. Equation (3) shows the discrete probabilities, $P\left(D_{k}=d\right)$ derived from the difference of accumulative probabilities $P_{D}\left[D_{i} \geq d\right]$.

$$
P\left(D_{k}=d\right)=P_{D}\left[D_{k} \geq d\right]-P_{D}\left[D_{k+1} \geq d\right]
$$

Influenced by the parameters of the beta distribution function, the estimation of damage can be determined as a continuous probability function. Figure $7 \mathrm{a}, \mathrm{b}$ shows the fragility curves by inputting a mean vulnerability index of $I_{v}^{c c}$ mean $=45.91$ and the mean vulnerability index plus the standard deviation value $\left(I_{v}^{c c}\right.$ mean $\left.+1 \sigma I_{v}^{c c}=54.26\right)$, respectively. 


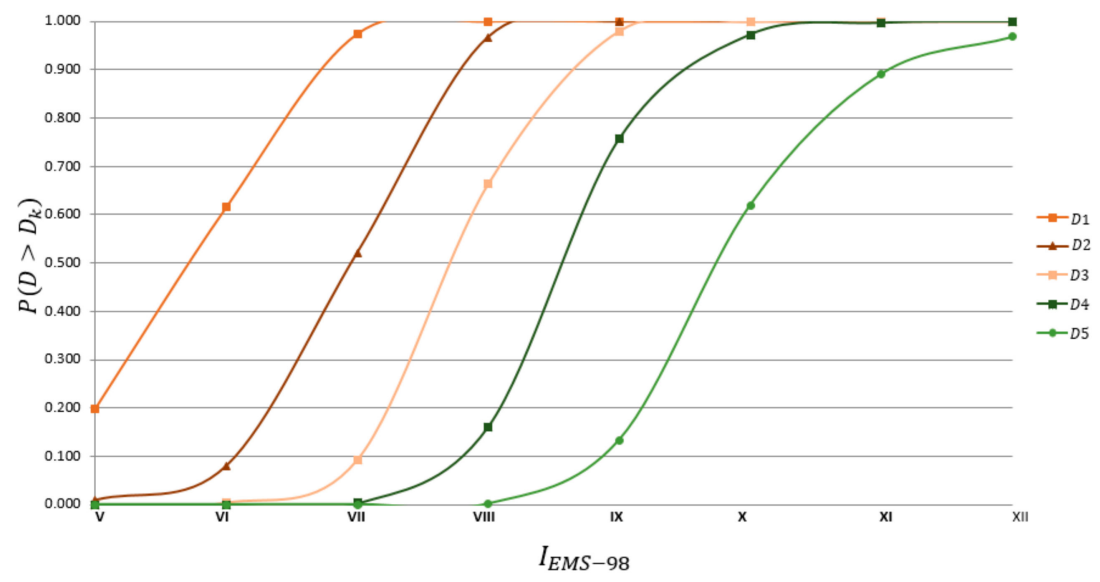

(a)

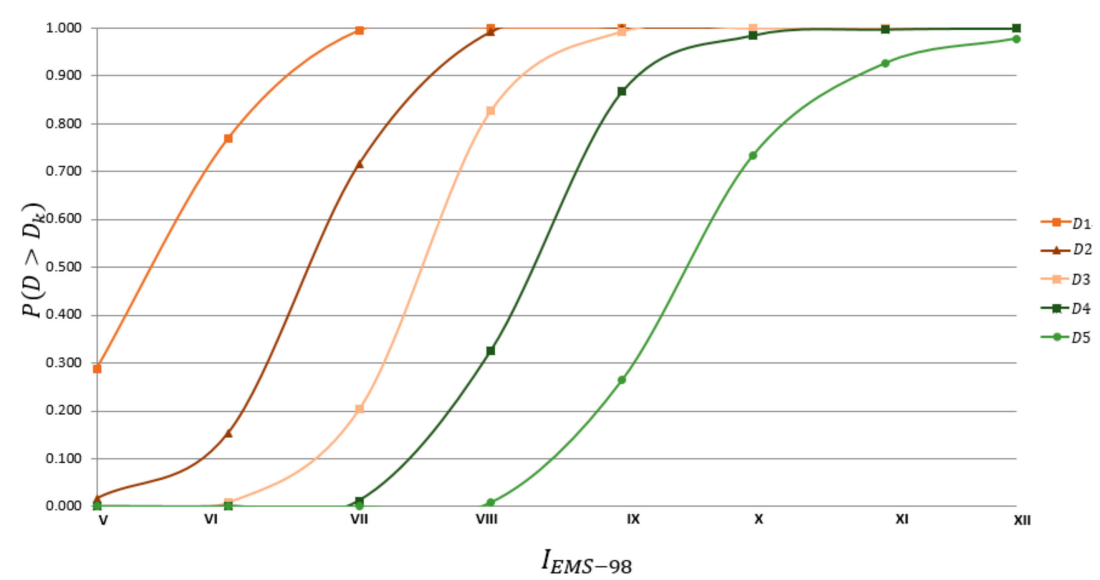

(b)

Figure 7. (a) Fragility curves for buildings $I_{v}^{c c}$ mean $=45.91$; (b) Fragility curves for buildings $I_{v}^{c c}$ mean $+1 \sigma I_{v}^{c c}=54.26$.

\subsection{Loss Estimation}

A wide variety of methods can be currently used to estimate material, human and economic losses [26-29]. From those, probabilistic-based approaches in which the probability of attaining a specific damage grade for a certain level of action are within the most widely adopted ones. According to these methods, the construction of a damage scenario can be completed through probabilistic distributions, whose input data computation involves the representative vulnerability index values $\left(I_{v}^{c c}\right.$ mean $-2 \sigma I_{v}^{c c} ; I_{v}^{c c}$ mean; $I_{v}^{c c}$ mean $-1 \sigma I_{v}^{c c} ; I_{v}^{c c}$ mean $+1 \sigma I_{v}^{c c} ; I_{v}^{c c}$ mean $\left.+2 \sigma I_{v}^{c c}\right)$. The loss estimation can be considered as part of a damage model, linking the physical damage grades. Thereby, the physical damage grades include the correlations between the probability of exceeding a certain level of damage and the probability of different loss phenomena. These methods are herein applied to estimate the probability of collapsed and unusable buildings or to assess the quantification of probable fatalities and severely injured people after a seismic event. 


\subsubsection{Collapsed and Unusable Buildings}

The method used to calculate the probability of collapsed and unusable buildings was proposed by Servizio Sismico Nazionale (SSN), based on the studies carried out by Bramerini et al. [30]. This approach involves the analysis of data associated with the probability of buildings, considered unusable after minor and moderate seismic actions.

Although such events produce lower levels of structural and non-structural damage, higher mean damage grade values are associated with a higher probability of building collapse. Thus, the probabilities of exceeding a certain damage grade are used in the loss estimation and are affected by multiplier factors, which range from 0 to 1 . The following Equations (4) and (5) were used for the computation of the probabilities of collapsed and unusable buildings, respectively:

$$
\begin{gathered}
P_{\text {collapse }}=P\left(D_{5}\right) \\
P_{\text {unusable buildings }}=P\left(D_{3}\right) \times W_{e i, 3}+P\left(D_{4}\right) \times W_{e i, 4}
\end{gathered}
$$

where $P\left(D_{i}\right)$, is the probability of occurrence at a certain damage grade (from $D_{1}$ to $D_{5}$ ), and $W_{e i, j}$ is the multiplier factor that indicates the percentage of buildings associated with $D_{i}$.

Although [30-33] have indicated different values for these factors, in this study, the values of $W_{e i, 3}$ and $W_{e i, 4}$ were assumed as equal to 0.4 and 0.6 , respectively. Figure $8 \mathrm{a}, \mathrm{b}$ presents the resultant probability of building collapse and unusable buildings, for the mean value of the vulnerability index $\left(I_{v}^{c c}\right.$ mean $\left.=45.91\right)$ and for other characteristic values of the vulnerability distribution $\left(I_{v}^{c c}\right.$ mean $-2 \sigma \sigma_{v}^{c c}$; $I_{v}^{c c}$ mean; $I_{v}^{c c}$ mean $-1 \sigma I_{v}^{c c} ; I_{v}^{c c}$ mean $+1 \sigma I_{v}^{c c} ; I_{v}^{c c}$ mean $\left.+2 \sigma I_{v}^{c c}\right)$, respectively. According to the results in Figure $8 \mathrm{a}$, the building collapse probability curve shows that the probabilities of collapse increase with the higher macroseismic value $I_{E M S-98}$. On the other hand, the number of unusable buildings (Figure 8b) decreases with the increase of seismic intensity, as a result of the ultimate state capacity producing the collapse, and thus its reduction.

The overall results from moderate to large intensity seismic events present an exponential rise between VIII and IX, as seen in Table 5, by considering macroseismic intensities from $I_{E M S-98}=$ VII to $I_{E M S-98}=X[19]$, and a mean vulnerability index of $I_{v}^{c c}$ mean $=45.91$; this output summarizes the number of units affected and the percentage related to the study area.

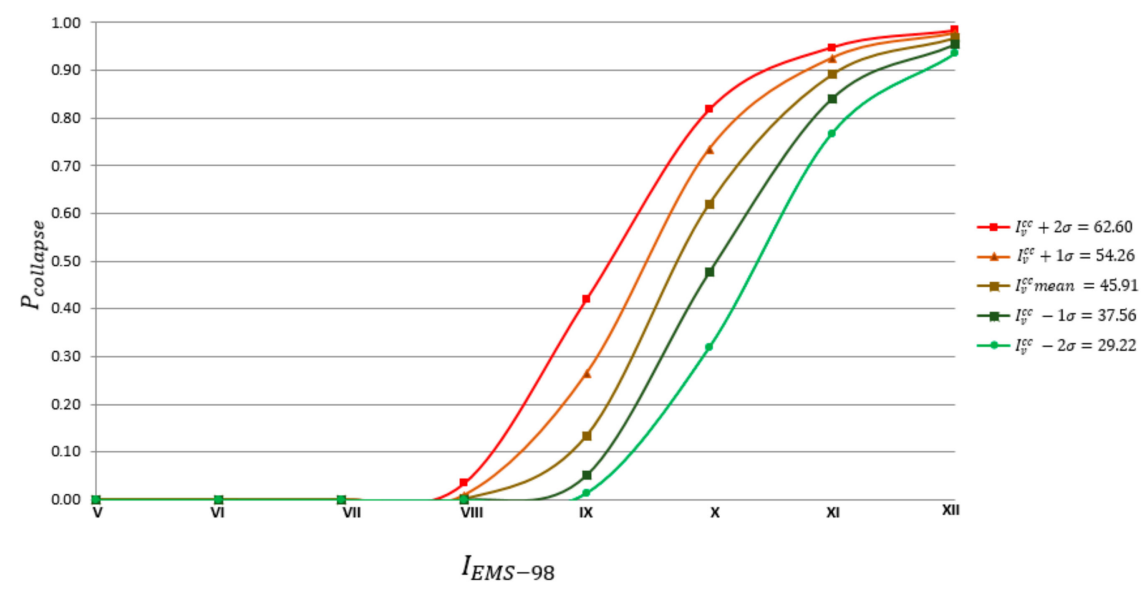

(a)

Figure 8. Cont. 


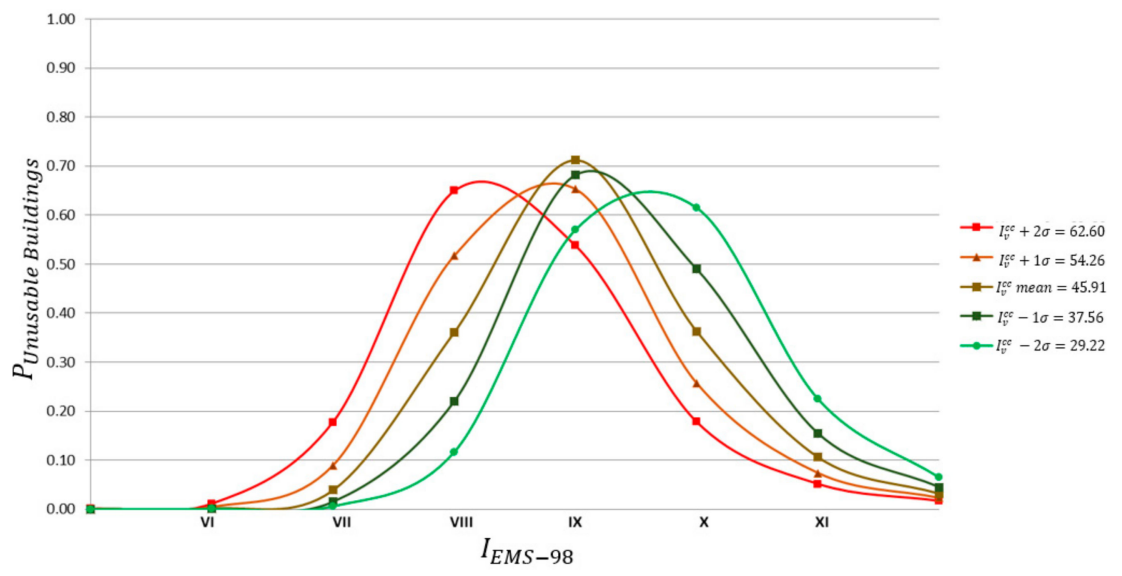

(b)

Figure 8. (a) Probability of collapse for different vulnerability values, $I_{v}^{c c}$ mean $=45.91$; (b) Probability of unusable buildings for different vulnerability values, $I_{v}^{c c}$ mean $=45.91$.

Table 5. Relative estimation of collapses and unusable buildings, $I_{v}^{c c}$ mean $=45.91$.

\begin{tabular}{ccccc}
\hline \multicolumn{5}{c}{ Macroseismic Intensities $I_{\text {EMS-98 }}$} \\
\hline Total Buildings = 166 & VII & VIII & IX & X \\
\hline Collapses & 0 & 0 & $22(13 \%)$ & $103(62 \%)$ \\
\hline Unusable buildings & $6(4 \%)$ & $60(36 \%)$ & $118(71 \%)$ & $60(36 \%)$ \\
\hline
\end{tabular}

\subsubsection{Human Casualties and Homelessness}

To estimate the probability of deaths, severe injuries associated with a disaster, and homelessness, the vulnerability index values are required, both the mean value of the vulnerability index $\left(I_{v}^{c c}\right.$ mean $\left.=45.91\right)$ and the representative values of the vulnerability distribution $\left(I_{v}^{c c}\right.$ mean $-2 \sigma I_{v}^{c c}$; $I_{v}^{c c}$ mean; $I_{v}^{c c}$ mean $-1 \sigma I_{v}^{c c} ; I_{v}^{c c}$ mean $+1 \sigma I_{v}^{c c} ; I_{v}^{c c}$ mean $\left.+2 \sigma I_{v}^{c c}\right)$. Hence, the calculation is carried out by resorting to Equations (6)-(8) [18].

$$
\begin{gathered}
P_{\text {death and severely injured }}=0.3 \times P\left(D_{5}\right) \\
P_{\text {homelessness }}=P\left(D_{3}\right) \times W_{e i, 3}+P\left(D_{4}\right) \times W_{e i, 4}+0.7 \times P\left(D_{5}\right) \\
P_{\text {homelessness }}=P_{\text {unusable buildings }}+0.7 \times P\left(D_{5}\right)
\end{gathered}
$$

where $P\left(D_{i}\right)$, is the probability of occurrence at a certain damage grade (from $D_{1}$ to $D_{5}$ ), $W_{e i, j}$ is the multiplier factor that indicates the percentage of buildings associated with $D_{i}$, and $D_{i}$ is the damage grade corresponding to collapse or are considered unusable.

In Equation (7), it is assumed that $30 \%$ of the population, located in a building expected to collapse (i.e., with a probability of exceeding damage grade $D_{5}$ ), will perish or be severely injured. The probability of homelessness is determined by the Equations (8) and (9), which considers that 100\% of people living in unusable buildings, and the remaining $70 \%$ of residents of collapsed buildings will not be able to reoccupy their dwellings after an earthquake [18]. Four seismic intensity scenarios, ranging between VII and X according to the EMS-98 scale [19], were analyzed, and the results were associated with the number of casualties and homeless. As can be observed in Table 6, the percentage of homelessness becomes relevant for intensity equal to or greater than VIII.

With this information, the extrapolation of loss output data for the Downtown area in Mexico City can be possible as a relative value. In other words, if these estimations were extended to the city center, it would have obtained a total number of 14,922 homeless people, which is undoubtedly a concerning 
result from the risk mitigation point of view. For that reason, appropriate logistical preparedness is required by the stakeholders (i.e., governmental authorities, civil protection, social entities) related to the relocation of residents, which could be performed through pre-seismic simulation exercises.

Table 6. Estimation of deaths, severely injured and homelessness, $I_{v}^{c c}$ mean $=45.91$.

\begin{tabular}{ccccc}
\hline \multicolumn{5}{c}{ Macroseismic Intensities $I_{E M S-98}$} \\
\hline Total People = 2291 & VII & VIII & IX & X \\
\hline $\begin{array}{c}\text { Death and severely } \\
\text { injured }\end{array}$ & 0 & $1(0.1 \%)$ & $94(4 \%)$ & $426(19 \%)$ \\
\hline Homelessness & $89(4 \%)$ & $829(36 \%)$ & $\begin{array}{c}1845 \\
(81 \%)\end{array}$ & $\begin{array}{c}1826 \\
(80 \%)\end{array}$ \\
\hline
\end{tabular}

To this end, a logistical plan is essential for having financial resources and thus suggesting the best emergency plan for the inhabitants. Communities and governments should put the same emphasis on planning for post-disaster emergency response by valuing community engagement and decision-making [25]. Figure 9 a shows the probability of casualties and Figure $9 \mathrm{~b}$ presents the probability of homelessness for different vulnerability values.

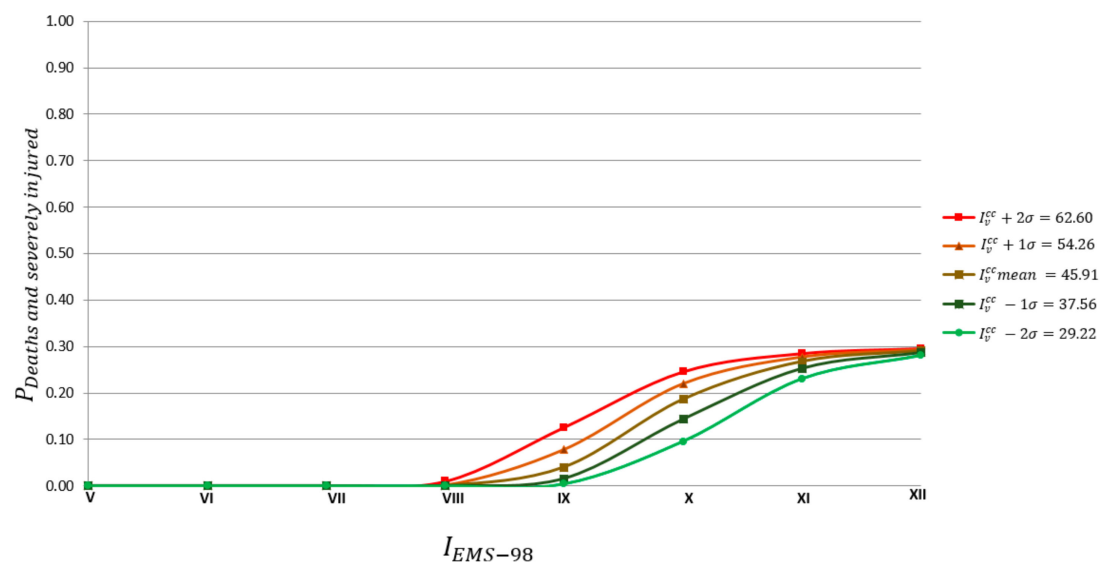

(a)

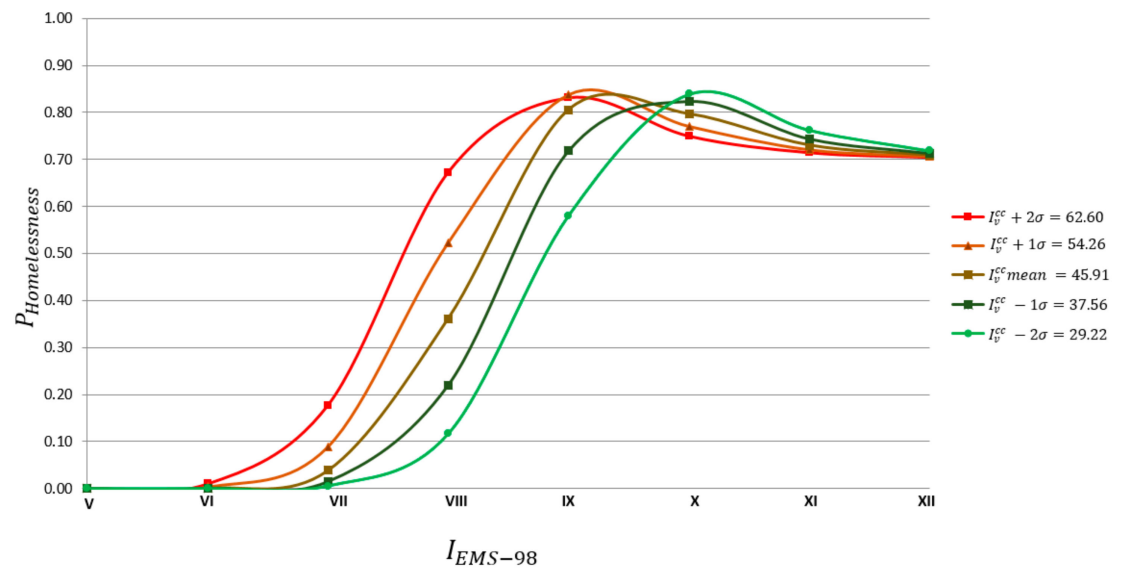

(b)

Figure 9. (a) Probability of casualties for different vulnerability values, $I_{v}^{c c}$ mean $=45.91$; (b) Probability of homeless for different vulnerability values, $I_{v}^{c c}$ mean $=45.91$. 


\subsubsection{Economic Losses and Repair Cost Estimation}

The estimated damage grade can either be interpreted economically, as defined by Benedetti and Petrini [34] or as an economic damage index, i.e., the ratio between the repair cost and the replacement cost. The correlation between damage grades and the repair and rebuilding costs is obtained through the processing of post-earthquake damage data [16]. According to Ferreira et al. [18], the repair cost probabilities for a certain seismic event characterized by intensity $\mathrm{I},(P[R \mid I])$ can be obtained from the product of the conditional probability of the repair cost for each damage level $\left(P\left[R \mid D_{k}\right]\right)$ with the conditional probability of the damage condition for each level of building vulnerability and seismic intensity $\left(P\left[D_{k} \mid I_{V}^{C C}, I\right]\right)$ given by the following Equation (9):

$$
P[R \mid I]=\sum_{D_{k}=1}^{5} \sum_{I_{v}^{C C}=0}^{100} P\left[R \mid D_{k}\right] \times P\left[D_{k} \mid I_{V}^{C C}, I\right]
$$

Loss estimation plays an essential role in the implementation of urban planning and retrofitting strategies, enabling costs to be placed alongside various beneficial measures such as reduced repair costs and life safety $[35,36]$. To estimate the repair costs associated with the different vulnerability values used in the loss evaluation ( $I_{v}^{c c}$ mean $-2 \sigma I_{v}^{c c} ; I_{v}^{c c}$ mean; $I_{v}^{c c}$ mean $-1 \sigma I_{v}^{c c} ; I_{v}^{c c}$ mean $+1 \sigma I_{v}^{c c} ; I_{v}^{c c}$ mean $\left.+2 \sigma I_{v}^{c c}\right)$, an average cost per unit area of $506 € / \mathrm{m}^{2}$ (about MXN 11,716/ $\mathrm{m}^{2}$ ) was considered for the building stock in Mexico City (according to BIMSA-Cámara Mexicana de la Industria de la Construcción, 2015). The estimated global repair costs for the 166 buildings analyzed in this work are illustrated in Figure 10 and summarized in Table 7 for the most relevant macroseismic intensities.

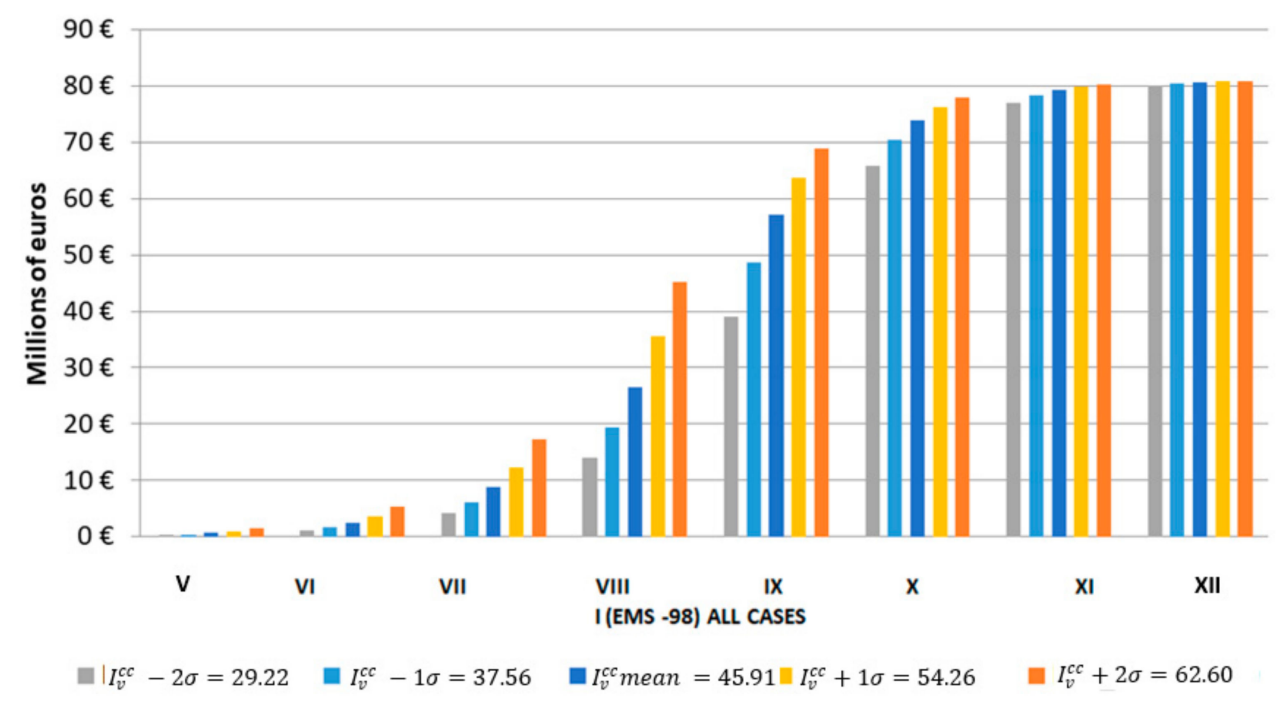

Figure 10. Estimation of repair cost in Euros and Mexican Pesos.

Table 7. Estimation of repair costs for macroseismic intensities VII, VIII, IX and X, $I_{\mathcal{v}}^{c c}$ mean $=45.91$.

\begin{tabular}{ccccc}
\hline \multicolumn{5}{c}{ Macroseismic Intensities $I_{E M S-98}$} \\
\hline VII & VIII & IX & X \\
\hline$€$ & $€ 8,746,309.63$ & $€ 26,602,900.82$ & $€ 57,049,885.22$ & $€ 73,855,900.17$ \\
\hline Mexican \$ & $\$ 202,914,383.43$ & $\$ 617,187,299.11$ & $\$ 1,323,557,337.03$ & $\$ 1,713,456,883.84$ \\
\hline
\end{tabular}

\section{Final Remarks}

A simplified seismic vulnerability assessment was applied to a set of historical buildings in the selected area of La Merced at Mexico City. Through an overall description of the study area, an index-based seismic vulnerability assessment methodology was applied to 166 buildings. To this 
purpose, 31 building typologies were originally defined through a matrix of four geometrical types and nine material types. From the analysis made, it was possible to observe that intrinsic characteristics of the buildings, such as their structural and geometrical features, their current conservation state and their location within the urban mesh are the factors that most contribute to their seismic vulnerability. Furthermore, it was possible to notice that, in several cases, massive incompatible refurbishment or retrofit interventions performed over the lifespan of the building also play a significant role in the increase of the seismic vulnerability of these buildings. From the vulnerability assessment results, a series of damage scenarios were also computed and plotted for the study area. Among those, the scenarios obtained for macroseismic intensities VII, VIII and IX were mapped resorting to a GIS tool in order to better understand and identify the buildings that, in the case of an earthquake within this range of intensities, will probably suffer more damage.

As a final remark, it is worth highlighting that the overall understanding of the selected area (i.e., historical context and characterization of the buildings), the vulnerability assessment, the computation of different damage scenarios and the estimation of losses are all valuable outputs that can be used by the local and national authorities to support the development of informed preand post-earthquake risk mitigation strategies. Moreover, these kinds of large-scale vulnerability assessment outputs can also guide the action of cultural institutions towards creating and fostering programs for the safeguarding of cultural heritage in historic areas.

Author Contributions: Conceptualization and methodology, T.M.F.; investigation, L.G.F.S.; writing-original draft preparation, L.G.F.S.; supervision, T.M.F.; funding acquisition, T.M.F. All authors have read and agreed to the published version of the manuscript.

Funding: This research was funded by the Portuguese Foundation for Science and Technology (FCT) through the postdoctoral grant SFRH/BPD/122598/2016.

Conflicts of Interest: The authors declare no conflict of interest.

\section{References}

1. Alizadeh, M.; Hashim, M.; Alizadeh, E.; Shahabi, H.; Karami, M.R.; Pour, A.B.; Pradhan, B.; Zabihi, H. Multi-Criteria Decision Making (MCDM) Model for Seismic Vulnerability Assessment (SVA) of Residential Buildings. Int. J. Geo-Inf. 2018, 7, 444. [CrossRef]

2. Alvarez, C.; Rivera, F.; Santa Maria, H.; Hube, M.A. Development of an exposure model of residential structures for Chile. In Proceedings of the Tenth Pacific Conference on Earthquake Engineering Building an Earthquake-Resilient Pacific, Sydney, NSW, Australia, 6-8 November 2015.

3. R-DMUCH; UNESCO; ICCROM. Disaster Risk Management of Cultural Heritage in Urban Areas; Research Center for Disaster Mitigation of Urban Cultural Heritage, Ritsumeikan University: Kyoto, Japan, 2013.

4. Tiziana, B.; Enea, D. Seismic and Energy Retrofit of the Historic Urban Fabric of Enna (Italy). Sustainability 2018, 10, 1138. [CrossRef]

5. Cherif, S.; Chourak, M.; Abed, M.; Douiri, A. Potential Seismic Damage Assessment of Residential Buildings in Imzouren City (Northern Morocco). Buildings 2018, 8, 179. [CrossRef]

6. Ridel, I.; Gueguen, P.; Dalla Mura, M.; Pathier, E.; Leduc, T.; Chanussot, J. Seismic vulnerability assessment of urban environments in moderate-to-low seismic hazard regions using association rule learning and support vector machine methods. Nat. Hazards 2015, 76, 1111-1141. [CrossRef]

7. QGIS Development Team. QGIS Geographic Information System Version 3.8.1 Zanzibar. Open Source Geospatial. Available online: http://qgis.osgeo.org (accessed on 6 December 2019).

8. Mayoral, J.M.; Asimaki, D.; Tepalcapa, S.; Wood, C.; Roman-de la Sancha, A.; Hutchinson, T.; Franke, K.; Montalva, G. Site effects in Mexico City basin: Past and present. Soil Dyn. Earthq. Eng. 2019, 121, 369-382. [CrossRef]

9. Cruz Atieza, V.M. Los Sismos. Una Amenaza Cotidiana; Instituto de Geofisica de la Universidad Nacional Autónoma de Mexico/Centro de Instrumentacion y Registro Sismico A.C., Cires, La Caja de Cerillos Ediciones S.A. de C.V: Mexico City, Mexico, 2013.

10. Garcia Acosta, V. Cinco Siglos de Movimientos. La Historia Sismica de la Ciudad de Mexico; Letras Libres: Mexico City, Mexico, 2017; pp. 25-27. 
11. Suarez, G.; Garcia Acosta, V. Los Sismos en la Historia de Mexico; UNAM/CIESAS/FCE: Mexico City, Mexico, 1996; Volume 1.

12. Reinoso Angulo, E. Riesgo Sismico de la Ciudad de Mexico. Especialidad Ingenieria civil; Academia de Ingenieria de Mexico: Mexico City, Mexico, 2007.

13. CENAPRED. Diagnostico de Peligros e Identificacion de Riesgos de Desastres en Mexico; Zepeda, O., Gonzalez, S., Eds.; Secretaria de Gobernacion, Centro Nacional de Prevencion de Desastres: Mexico City, Mexico, 2001.

14. CENAPRED. Folleto Sismos; Secretaria de Gobernacion: Mexico City, Mexico, 2014.

15. Kostoglodov, V.; Francisco, J. Cien Años de sismicidad en Mexico. Available online: http://usuarios.geofisica. unam.mx/vladimir/sismos/100a\%F1os.html (accessed on 4 April 2017).

16. Correia Lopes, G.; Vicente, R.; Ferreira, T.M.; Azenha, M. Intervened URM buildings with RC elements: Typological characterisation and associated challenges. Bull. Earthq. Eng. 2019, 17, 4987-5019. [CrossRef]

17. GNDT. Scheda di Esposizione e Vulnerabilita e di Rilevamento Danni di Primo Livello e Secondo Livello (Muratura e Cemento Armato); Gruppo Nazionale per la Difesa dai Terremoti: Rome, Italy, 1994.

18. Ferreira, T.M.; Vicente, R.; Mendes da Silva, J.A.R.; Varum, H.; Costa, A. Seismic vulnerability assessment of historical urban centres: Case study of the old city centre in Seixal, Portugal. Bull. Earthq. Eng. 2013, 11, 1753-1773. [CrossRef]

19. Grüntal, G. European Macroseismic Scale 1998 (EMS-98) European Seismological Commission, Subcommission on Engineering Seismology; Cahiers du Centre Europeen de Geodynamique et de Seismologie, Working Group Macroseismic Scales: Brussels, Belgium, 1998.

20. Aguado, J.L.P.; Ferreira, T.M.; Lourenço, P.B. The Use of a Large-Scale Seismic Vulnerability Assessment Approach for Masonry Façade Walls as an Effective Tool for Evaluating, Managing and Mitigating Seismic Risk in Historical Centers. Int. J. Archit. Herit. 2018, 12, 1259-1275. [CrossRef]

21. Bonnett Díaz, R.L. Vulnerabilidad y Riesgo Sismico de Edificios. Aplicación a entornos urbanos en zonas de amenaza alta y moderada. PhD Thesis, Universitat Politècnica de Catalunya, Barcelona, Spain, December 2003.

22. Bernardini, A.; Giovinazzi, S.; Largomasino, S.; Parodi, S. Vulnerabilita e previsione di danno a scala territoriale secondo una metodologia macrosismica coerente con la scala EMS-98. Proceedings of XII Convegno Nazionale l'ingegneria sismica ANIDIS, Pisa, Italy, 10-14 June 2007; pp. 10-14.

23. Lagomarsino, S.; Giovinazzi, S. Macroseismic and mechanical models for the vulnerability and damage assessment of current buildings. Bull. Earthq. Eng. 2006, 4, 415-443. [CrossRef]

24. Arnal Simon, S.; Betancourt Suarez, M. Normas Tecnicas Complementarias para Diseno Por Sismo. In Reglamento de Construcciones para el Distrito Federal: Actualizado, Ilustrado y Comentado, 9th ed.; Trillas: Mexico City, Mexico, 2017.

25. Maio, R.; Ferreira, T.M.; Vicente, R.; Estêvão, J. Seismic vulnerability assessment of historical urban centres: Case study of the old city centre of Faro, Portugal. J. Risk Res. 2015, 19, 1-30. [CrossRef]

26. Guettiche, A.; Guéguen, P.; Mimoune, M. Economic and Human Loss Empirical Models for Earthquakes in the Mediterranean Region, with Particular Focus on Algeria. Int. J. Disaster Risk Sci. 2017, 8, 415-434. [CrossRef]

27. Jaiswal, K.; Wald, D. An Empirical Model for Global Earthquake Fatality Estimation. Earthq. Spectra 2010, 26, 1017-1037. [CrossRef]

28. Jaiswal, K.; Wald, D.J. Estimating Economic Losses from Earthquakes Using an Empirical Approach. Earthq. Spectra 2013, 29, 309-324. [CrossRef]

29. Heatwole, N.; Rose, A. A reduced-form rapid economic consequence estimating model: Application to property damage from U.S. earthquakes. Int. J. Disaster Risk Sci. 2013, 4, 20-32. [CrossRef]

30. Bramerini, F.; Di Pasquale, G.; Orsini, A.; Pugliese, A.; Romeo, R.; Sabetta, F. Rischio Sismico del Territorio Italiano. Proposta per una Metodologia e Risultati; Servizio Sismico Nazionale SSN/RT/95/01: Roma, Italy, 1995.

31. HAZUS. Earthquake Loss Estimation Methodology_Technical and User Manuals; Federal Emergency Management Agency: Washington, DC, USA, 1999.

32. ATC-13. Earthquake Damage Evaluation Data for California; Applied Technology Council: Redwood City, CA, USA, 1985.

33. Dolce, M.; Kappos, A.; Masi, A.; Penelis, G.; Vona, M. Vulnerability assessment and earthquake damage scenarios of the building stock of Potenza (Southern Italy) using Italian and Greek methodologies. Eng. Struct. 2006, 28, 357-371. [CrossRef] 
34. Benedetti, D.; Petrini, V. On Seismic Vulnerability of Masonry Buildings: Proposal of An Evaluation Procedure. Ind. Constr. 1984, 18, 66-78.

35. Spence, R.; D'Ayala, D. Damage assessment and analysis of the 1997 Umbria-Marche earthquakes. Struct. Eng. Int. 1999, 9, 229-233. [CrossRef]

36. Maio, R.; Estêvão, J.M.C.; Ferreira, T.M.; Vicente, R. The seismic performance of stone masonry buildings in Faial island and the relevance of implementing effective seismic strengthening policies. Eng. Struct. 2017, 141, 41-58. [CrossRef]

(C) 2020 by the authors. Licensee MDPI, Basel, Switzerland. This article is an open access article distributed under the terms and conditions of the Creative Commons Attribution (CC BY) license (http://creativecommons.org/licenses/by/4.0/). 